\title{
GEOGRAPHICALLY WEIGHTED REGRESSION APPROACH FOR SHALLOW WATER DEPTH ESTIMATION USING MULTISPECTRAL SATELLITE IMAGERIES
}

\author{
Y. A. Lumban-Gaol ${ }^{1,2 *}$, R. S. Dewi ${ }^{2}$, N. Oktaviani ${ }^{2}$, S. Aditya ${ }^{2}$ \\ ${ }^{1}$ Delft University of Technology, Netherlands - yustisiardhitasari@gmail.com \\ ${ }^{2}$ Geospatial Information Agency (BIG), Jl. Raya Jakarta-Bogor Cibinong, Indonesia - (ratna.sari, nadya.oktaviani, \\ sandi.aditya)@big.go.id
}

Commission III

KEY WORDS: bathymetry, shallow water, multispectral, SDB, GWR

\begin{abstract}
:
Shallow water depth is essential for coastal planning, monitoring, and research. Bathymetry data is mostly produced from hydrographic survey using echosounder. The generic result from those measurements is discrete values while the desired output is a continuous depth model. To fill the gaps in the sounding data, we use Satellite Derived Bathymetry (SDB) approach with Geographically Weighted Regression (GWR). This study aims to investigate the feasibility of GWR to model bathymetry of shallow water in the eastern part of Indonesia. We explore the correlation between the number of training data and the predicted result. Two different satellites images are used, namely: Sentinel-2A and Landsat 8 OLI/TIRS with 10 and $30 \mathrm{~m}$ resolutions respectively. For the experiment, in-situ data are set into training and validation in three different ratios. The model is developed using adaptive GWR approach in which the parameter of regression would adapt the local data set within different kernel sizes. Finally, we compute RMSE (Root Mean Square Error), $\mathrm{R}^{2}$, and TVU (Total Vertical Uncertainty) to assess the quality of our model. In general, Sentinel-2A produces more detailed information due to higher resolution than Landsat 8 OLI/TIRS. Sentinel-2A also obtains more accurate results based on RMSE values. The percentage number of the estimated depth that fulfils TVU requirements is up to $83 \%$. These assessment quality results give us an insight that the SDB approach using GWR is promising. Thus, the GWR method may be able to provide an estimate of bathymetry for many coastal areas in Indonesia.
\end{abstract}

\section{INTRODUCTION}

The advent of Satellite Derived Bathymetry (SDB) approaches to model sea-water depth could contribute to bathymetry mapping using in-situ measurements. The sea-water depth is determined by hydrographic survey using echosounder instrument installed on the ship. The ships need to sweep the area within a specific sounding line and frequency. Mapping the whole water area is expensive and takes a lot of time. Moreover, in the shallow water area, this method is challenging due to the difficulty of the ship to perform the survey. The safety issues from both vessels and underwater objects become a burden, especially in observing some particular shallow water with coral reefs formations. Meanwhile, shallow water depth information is important for coastal development planning, modelling, monitoring, and coastal research. Thus, multispectral remote sensing approaches to estimate depth have been proposed as alternative methods, especially to fill the gaps between sounding line from the survey.

The Indonesian Geospatial Information Agency (BIG) performs a bathymetry survey and use the obtained data as the main resource to build a bathymetry model. As the only institution responsible for marine and coastal mapping in Indonesia, BIG is required to deliver marine maps in large quantities. The survey in shallow water area is mostly performed with Single Beam Echosounder (SBES). The results are depth points, but the end products of the depth model are a raster-based model. Another alternative is to use SDB approach to fill the gaps obtained from sounding survey and produce the shallow water depth model as raster. Therefore, BIG needs to undertake necessary research to understand the lowest level of error which can be obtained through the implementation of SDB algorithm. Moreover, to understand whether SDB could give benefit to BIG's marine maps relative to conventional SBES measurements is also critical.

This study is focusing on the implementation of Geographically Weighted Regression (GWR) method by concerning the number of training data needed for SDB approach and the quality of the model as described in the literature (Bramante, Raju, \& Sin, 2013; Hamylton, Hedley, \& Beaman, 2015; Manessa, Haidar, Hartuti, \& Kresnawati, 2018; Mishra, Narumalani, Rundquist, \& Lawson, 2013; Sagawa, Yamashita, Okumura, \& Yamanokuchi, 2019; Said, Mahmud, \& Hasan, 2017). Detail explanations are given in the next section. In this research, we defined shallow water area depth ranging from 0 to 35 meter. We tested the performance of GWR to the proportion of training data set that used to determine the SDB model. Furthermore, we also compared the performance of GWR model between two satellite images, namely Sentinel-2A and Landsat 8 OLI/TIRS.

\section{RELATED WORK AND MOTIVATIONS}

The principal of optical satellite remote sensing bathymetry is the total amount of radioactive energy reflected from water column which is a function of water depth. In addition, the attenuation of light in the water column is a function of wavelength where the shorter wavelength attenuates less than the longer wavelength. The bottom reflectance can be transformed into depth values after removing the atmospheric scattering, surface reflection, and inwater scattering components (Vinayaraj, Raghavan, \& Masumoto, 2016).

The utilization of remote sensing for mapping the water depth had been introduced by Polcyn in 1969. He used ratio algorithms of a pair of bands to find the correlation with water depth (Polcyn

* Corresponding author 
\& Rollin, 1969). A decade further, Lyzenga modified the algorithm to include the effect of scattering in the water and the internal reflection at the water surface (Lyzenga, 1978) and he continuously upgraded the method (Lyzenga, 1985; Lyzenga, Malinas, \& Tanis, 2006). Some research had been done by modifying Lyzenga methods by adding a spatial component in the Lyzenga's equation to improve the accuracy (Kanno, Koibuchi, \& Isobe, 2012; Kanno, Tanaka, Kurosawa, \& Sekine, 2013; Kanno \& Tanaka, 2012).

Similar approaches for Indonesian water have also been conducted, but with other regression methods (Dewi et al., 2019; Manessa et al., 2016; Wicaksono, 2015). However, we argue that study on another approach is still necessary to find the optimum algorithm and model with a good data fit between in-situ data and the related SDB model.

\section{MATERIALS AND METHODS}

In this section, we introduce the study area and data sets that we used for this research. General workflow is introduced in Figure 1 and the details of each step are explained in the following subsections. In general, our study starts from data acquisition, satellite image correction, separation of in-situ data set, estimating shallow water depth, to quality assessment.

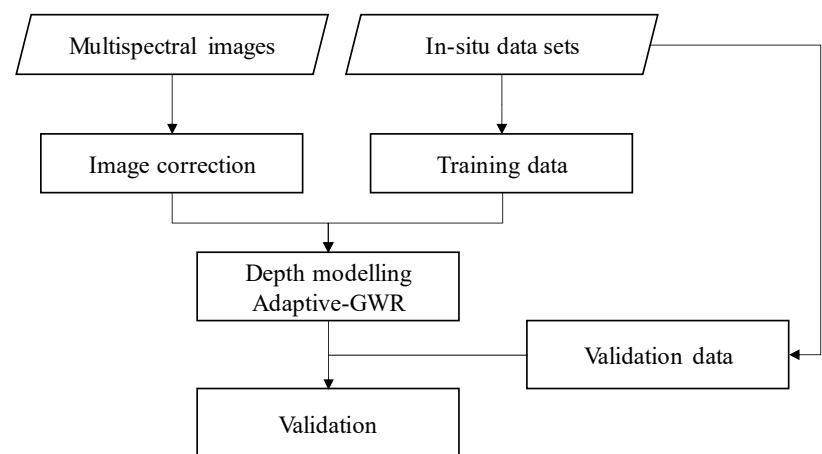

Figure 1. General workflow of this study.

\subsection{Study Area and Data}

The research was conducted on the small islands in the south part of Morotai Island, Maluku Utara, Indonesia. For the experiments, the area was divided into three Area of Interest (AoI) as shown in Figure 2. The first AoI (AoI-1), named Zum Zum Island, covers about $7 \mathrm{~km}^{2}$. The second and third AoI are in Galo Galo village and covers roughly $5 \mathrm{~km}^{2}$ each. This area was chosen due to the availability of in-situ data and the clear water condition. Also, it has a variation of depth, both shallow and deep water.

The nearest tides station from the study area is in Juanga, about $7 \mathrm{~km}$ from AoI-1 and $15 \mathrm{~km}$ from AoI-2 and Aoi-3. Juanga tide varies from $-0.361 \mathrm{~m}$ to $1.905 \mathrm{~m}$ (Center for Geodesy and Geodynamic Control Network, 2020). By considering the short distance between the AoIs and Daruba, we assume that tides in the study area are similar to Daruba. The waters itself have a clear condition and contains sand and corals.

In-situ data depth was acquired from Single Beam Echosounder (SBES) survey held by Indonesian Geospatial Information Agency. The survey was performed in October 2018 with sounding line distance $200 \mathrm{~m}$ and sounding frequency $1 \mathrm{~s}$. The final product was depth points with reference to Mean Sea Level (MSL). The depth ranges for AoI-1, AoI-2, and AoI-3 respectively are $3.092 \mathrm{~m}-35.222 \mathrm{~m}, 3.042 \mathrm{~m}-27.072 \mathrm{~m}$, and $3.002 \mathrm{~m}-29.732 \mathrm{~m}$ below the MSL.

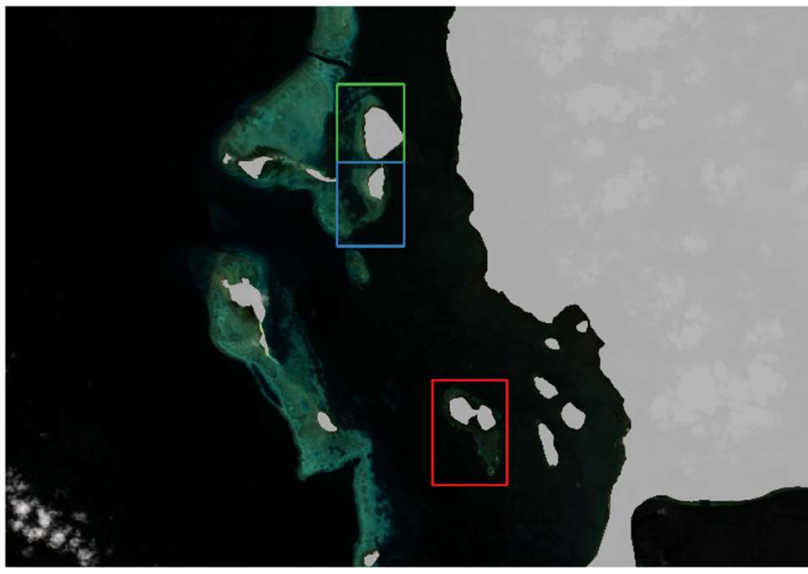

Figure 2. Area of Interest (AoI) in this study. AoI-1 (red box), AoI-2 (blue box), AoI-3 (green box).

This study used two multispectral images that have variation in spatial resolution (Table 1). We chose Landsat 8 OLI/TIRS and Sentinel-2A with band combinations, namely: blue, green, and red. Both images had the same acquisition date and covered all area in this study.

\begin{tabular}{|c|c|c|c|c|}
\hline $\begin{array}{l}\text { Image } \\
\text { type }\end{array}$ & $\begin{array}{c}\text { Image } \\
\text { acquisition } \\
\text { date }\end{array}$ & $\begin{array}{l}\text { Pixel } \\
\text { size }\end{array}$ & $\begin{array}{l}\text { Spectral } \\
\text { attributes } \\
(\mathrm{nm})\end{array}$ & $\begin{array}{c}\text { Geometric } \\
\text { attributes }\end{array}$ \\
\hline $\begin{array}{l}\text { Landsat } 8 \\
\text { OLI/TIRS }\end{array}$ & $\begin{array}{l}9 \text { August } \\
2017\end{array}$ & $30 \mathrm{~m}$ & $\begin{array}{c}\text { Blue (452- } \\
512), \text { green } \\
(533-590), \\
\text { red }(636- \\
673)\end{array}$ & Level 1T \\
\hline $\begin{array}{c}\text { Sentinel- } \\
2 \mathrm{~A}\end{array}$ & $\begin{array}{l}9 \text { August } \\
2017\end{array}$ & $10 \mathrm{~m}$ & $\begin{array}{c}\text { Blue (490), } \\
\text { green }(560), \\
\text { red }(665)\end{array}$ & Level 1C \\
\hline
\end{tabular}

Table 1. Image data sets used in this study.

The images were downloaded freely from https://earthexplorer.usgs.gov/. Landsat 8 OLI/TIRS Level-1T image is a radiometrically and geometrically corrected (Geological Interior Survey, 2016). Sentinel-2A Level-1C image had gone through geometric ortho-correction and providing ToA Reflectance.

\subsection{Satellite Image Correction}

The radiance value includes four components, that is atmospheric scattering, surface reflection, in-water volume scattering, and bottom reflection. The estimation of depth is performed by using bottom reflectance value. This value can be obtained after removing the other three components. As deeper the water as weaker the signal attenuates through it. Therefore, deep water does not include bottom reflectance component due to its depth (Vinayaraj et al., 2016). Thus, the correction can be obtained by using the average radiance at deep water area. The area of the deep water should be specified first. The easiest way to do this was by looking at the images visually. The darker the images, the deeper the depth. Or, systematically calculates the minimum radiance value. The corrected spectral value is given by (Green, Mumby, Edwards, \& Clark, 2000):

$$
X(\lambda)_{i}=\log \left(L(\lambda)_{i}-\operatorname{mean}\left(L_{\infty}(\lambda)_{i}\right)\right)
$$

where $X(\lambda)_{i}$ is corrected spectral value of band $\lambda$ at $i$ th point, $L(\lambda)_{i}$ is the spectral value in shallow water, and $L_{\infty}(\lambda)_{i}$ is the spectral value in the deep water. 


\subsection{Training and Validation Data}

The in-situ data become the reference in the validation process. Then, we need to separate those data into training and validation data sets. Training data is then used to calculate the coefficient regression and the rest is used to assess the quality of the results. The problem is about how to find the optimum amount of in-situ data needed to build the optimum model. Therefore, in this study we split the in-situ data in each AoI into three training data sets based on the percentage of all data, namely: $75 \%, 50 \%$, and $25 \%$. The remaining in-situ data that is not included in the prediction would be used for validation purposes.

\subsection{Depth Estimation Modelling}

The corrected spectral values from images are correlated with reference depth values from SBES using a regression algorithm to derive shallow water depth. Several statistical approaches can be used, such as simple linear regression and multiple linear regression or global model. In general, these methods calculate the regression parameters value first, then this value is used in the equation to predict the depth value in each pixel. However, these parameters of regression are still homogeneous, meaning that they are the same for every pixel of the image. That is called global model. However, the regression technique generally depends on the density of the data used. So, when the density is varied, the result would not indicate the spatial relationship between data distribution and the parameters. To address this issue, Brunsdon, Fotheringham, \& Charlton (1996) proposed a method called Geographically Weighted Regression (GWR). GWR is a relative simple technique that extends the traditional regression framework by allowing local rather than global parameters to be estimated (Fotheringham, Charlton, \& Brunsdon, 1998).

The variables in this study consist of the depth value from SBES, called reference depth, and the spectral value of each band in each pixel. The parameters to be determined was the coefficient of regression. The predicted value to be obtained was the depth value in each pixel images. The global regression model is given by (Fotheringham et al., 1998):

$$
D_{i}=\beta_{0}+\sum_{n} \beta_{n} X(\lambda)_{n i}
$$

and the GWR model is given by (Binbin et al., 2019):

$$
D_{i}=\beta_{0(x, y)}+\sum_{n} \beta_{n(x, y)} X(\lambda)_{n i}
$$

where $D_{i}$ is the known depth, $\beta_{0}$ is the intercept, $\beta_{n}$ is the coefficient of regression, $(x, y)$ is the coordinates of the $n$th point, and $X(\lambda)_{n i}$ is corrected spectral value at the pixel $i$ of $n$th point. The difference between equation (2) and (3) lies in the $\beta$ value. In the global model, the coefficient of regression did not express the local heterogeneity as in the GWR model. It means the $\beta$ value in the global model had the same value at each pixel.

Meanwhile, GWR model is a weighted regression model that computes coefficient for each pixel. The coefficients are determined using a moving kernel and pixels close to the centroid are assigned higher weights than the pixels away from the centroid (Vinayaraj, 2017). In general, the weighting schemes are classified as discrete and continuous depending on the function used. The most important thing to be considered was the spatial coverage of the kernel (bandwidth) because it will take effect on the weighting.
The bandwidth can be set as fixed or adaptive. Fixed GWR used only one size of bandwidth in each kernel. Meanwhile, in Adaptive GWR, the size of the kernel is vary based on the density of the reference depths where it becomes smaller when the reference points are denser and vice versa (Vinayaraj et al., 2016). Due to the uneven distribution of the reference points, this study used Adaptive GWR (AGWR) method to predict the depth. For data processing, we used GW model in R package, detail of GW model can be found in several previous studies (Binbin et al., 2019; Gollini, Lu, Charlton, Brunsdon, \& Harris, 2015; Lu, Harris, Charlton, \& Brunsdon, 2014).

\subsection{Estimated Depth Validation}

To evaluate the quality of the implementation, the estimated depth values produced from the AGWR models were compared with the in-situ depth validation data sets. Here we used a standard approach to measure the accuracy of quantitative data by estimating the Root Mean Square Error (RMSE):

$$
R M S E=\sqrt{\frac{\sum_{1}^{n}\left(d_{r e f}-d_{p r e d}\right)^{2}}{n}}
$$

where $d_{\text {ref }}$ and $d_{\text {pred }}$ are in-situ and predicted depth values respectively at the same horizontal position in the validation data, and $\mathrm{n}$ is the number of validation data used in this step.

To address the variance of the estimated and reference (validation) values, we compute the coefficient of determination $\left(\mathrm{R}^{2}\right)$. In addition, IHO S-44 (International Hydrographic Organization, 2008) provides a specification to compute Total Vertical Uncertainty (TVU). TVU specifies the maximum allowable values with $95 \%$ confidence level under a certain order. The computation is actually for echosounder or bathymetric LIDAR measurement. We used this approach to evaluate our model from IHO standard perspective. When we obtained the TVU values from our model, we then counted how many data in our model that have values below these related TVU values. As for the maximum allowable TVU was calculated as (International Hydrographic Organization, 2008):

$$
T V U=\sqrt{a^{2}+(b \times d)^{2}}
$$

where $a$ represents that portion of uncertainty that does not vary with depth, $b$ is a coefficient which represents that portion of the uncertainty that varies with depth, and $d$ is the depth from the model. This study focused on shallow water depth below $100 \mathrm{~m}$, so our model was categorized as Order 1 where the constant value $a=0.5 \mathrm{~m}$ and $b=0.013$.

\section{RESULTS AND DISCUSSION}

From the experiment, we found that performing GWR on Sentinel-2A provided a better result than Landsat 8 OLI/TIRS images (see Table 2). The RMSE values of Sentinel-2A range from $0.505-1.77 \mathrm{~m}$ while by using Landsat 8 OLI/TIRS, the RMSE values are between $0.764-1.753 \mathrm{~m}$ as can be seen in Table 2. The RMSE values of Landsat 8 OLI/TIRS are 23 - $48 \%$ higher than the RMSE values of Sentinel-2A.

In addition, by setting training data into $75 \%$ tends to produce a good accuracy for Sentinel-2A while for Landsat 8 OLI/TIRS, this does not apply (see Figures $3 \mathrm{a}$ and $3 \mathrm{c}$ ). For Sentinel-2A, with $75 \%$ training data, we obtained RMSE values ranging from 0.505 $-1.272 \mathrm{~m}$, while by decreasing training data proportion into $50 \%$ and $25 \%$, tends to reduce the accuracy of the model into 0.623 $1.323 \mathrm{~m}$, and $0.808-1.770 \mathrm{~m}$, respectively. 


\begin{tabular}{|c|c|c|c|}
\hline $\begin{array}{c}\text { Training } \\
\text { Data } \\
\text { Proportion }\end{array}$ & AoI & Rentinel-2A & $\begin{array}{c}\text { Landsat } 8 \\
\text { OLI/TIRS }\end{array}$ \\
\cline { 3 - 4 } & & & 1.416 \\
& 1 & 0.723 & 0.764 \\
& 2 & 0.505 & 1.753 \\
\hline $50 \%$ & 3 & 1.272 & 1.345 \\
& 1 & 0.707 & 0.812 \\
& 2 & 0.623 & 1.730 \\
\hline $25 \%$ & 1 & 0.944 & 1.342 \\
& 2 & 0.808 & 1.071 \\
& 3 & 1.770 & 1.376 \\
\hline
\end{tabular}

Table 2. The RMSE values when performing GWR on various data set.
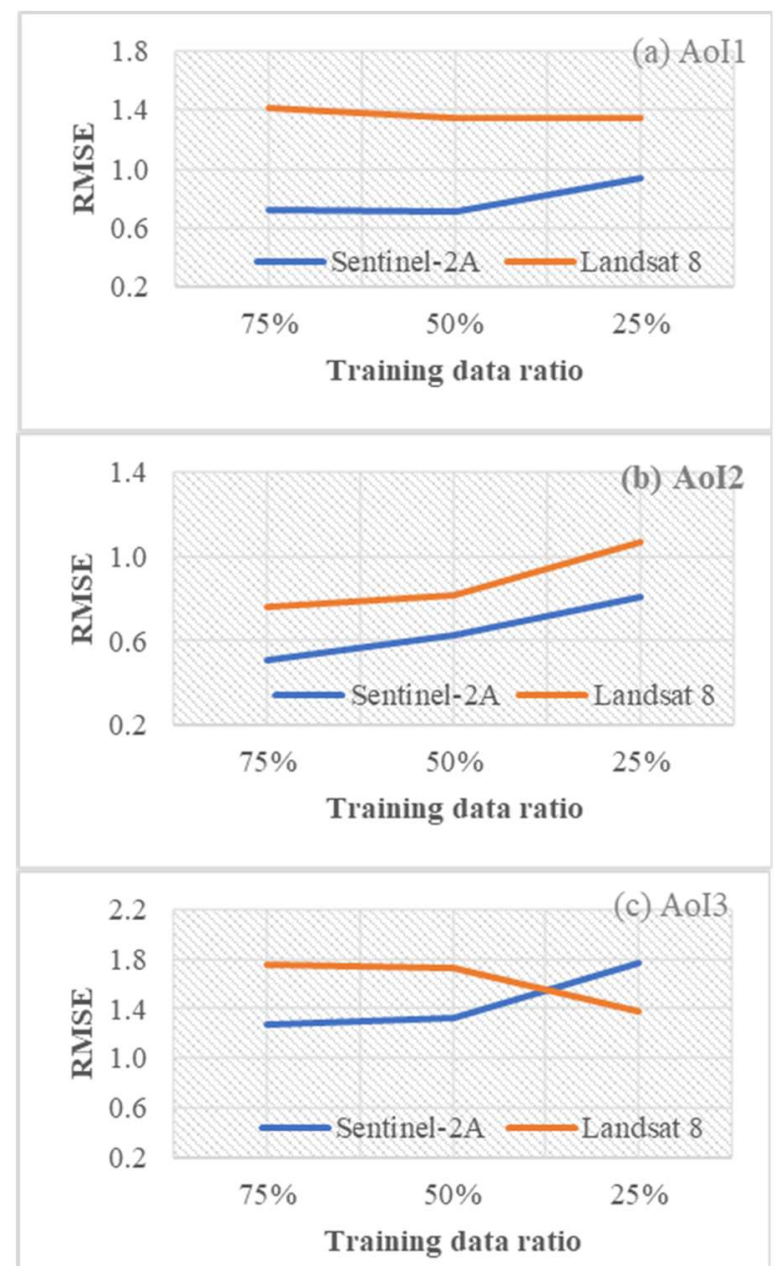

Figure 3. The graphs depicting the RMSE values for each AoI with various training ratios.

As for the variance, $\mathrm{R}^{2}$ values range from 0.95 to 0.99 for all AoI and all combination ratios of training data implying that the estimated values fit well with the reference values. However, when we checked the quality of our SDB model by calculating the TVU values, we obtained varying values of TVU (see Table $3)$. In this case, the proportion of training data still resulted in a linear trend. The larger the proportion of training data used, the higher the percentages of TVU which meet the requirement of
95\% confidence level. In general, the SDB model from Sentinel$2 \mathrm{~A}$ obtained better TVU results compared to Landsat 8 OLI/TIRS.

\begin{tabular}{|c|c|c|c|c|}
\hline \multirow{2}{*}{ Images } & \multirow{2}{*}{ AoI } & \multicolumn{3}{|c|}{ Overall TVU for each training ratio } \\
\cline { 3 - 5 } & & Train75\% & Train50\% & Train25\% \\
\hline \multirow{2}{*}{$\begin{array}{c}\text { Sentinel- } \\
\text { 2A }\end{array}$} & AoI-1 & $75 \%$ & $77 \%$ & $64 \%$ \\
& AoI-2 & $83 \% *$ & $75 \%$ & $68 \%$ \\
& AoI-3 & $60 \%$ & $55 \%$ & $45 \%$ \\
\hline \multirow{2}{*}{ Landsat 8 } & AoI-1 & $59 \%$ & $62 \%$ & $62 \%$ \\
OLI/TIRS & AoI-2 & $70 \% *$ & $68 \%$ & $58 \%$ \\
& AoI-3 & $46 \%$ & $46 \%$ & $51 \%$ \\
\hline
\end{tabular}

Table 3. The overall TVU values for each training ratio; the asterisk symbols present the highest TVU values for each image.
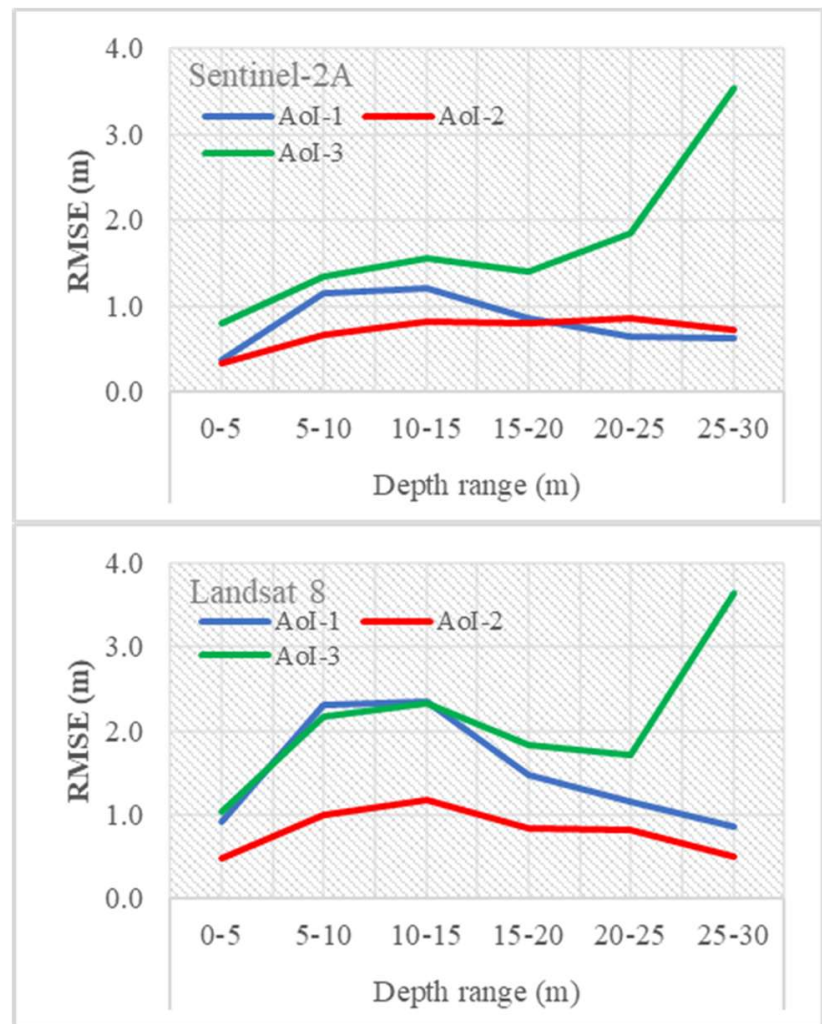

Figure 4. The RMSE values for each $5 \mathrm{~m}$ range of depth.

We further evaluated the accuracies in terms of RMSE at each depth range as in Figures 4 . Both Sentinel-2A and Landsat 8 OLI/TIRS obtained the best performance at depth range 0-5 m. Up to $15 \mathrm{~m}$, it was obvious that by the increase of the depth, the accuracy of SDB models become worst. This may be due to the capability of sensors in capturing information in the water area is limited by the increasing depth (Geyman \& Maloof, 2019). In contrast, at depth range 15 to $25 \mathrm{~m}$, the SDB model obtained a good accuracy result. It was not clear to us why the accuracy of the model become better by the increasing depth. Even though, it is stated that SDB model can extract depth information until 30 $\mathrm{m}$ in clear water (Evagorou, Mettas, Agapiou, Themistocleous, \& Hadjimitsis, 2019), further evaluation on the consistency of this GWR algorithm is required. 

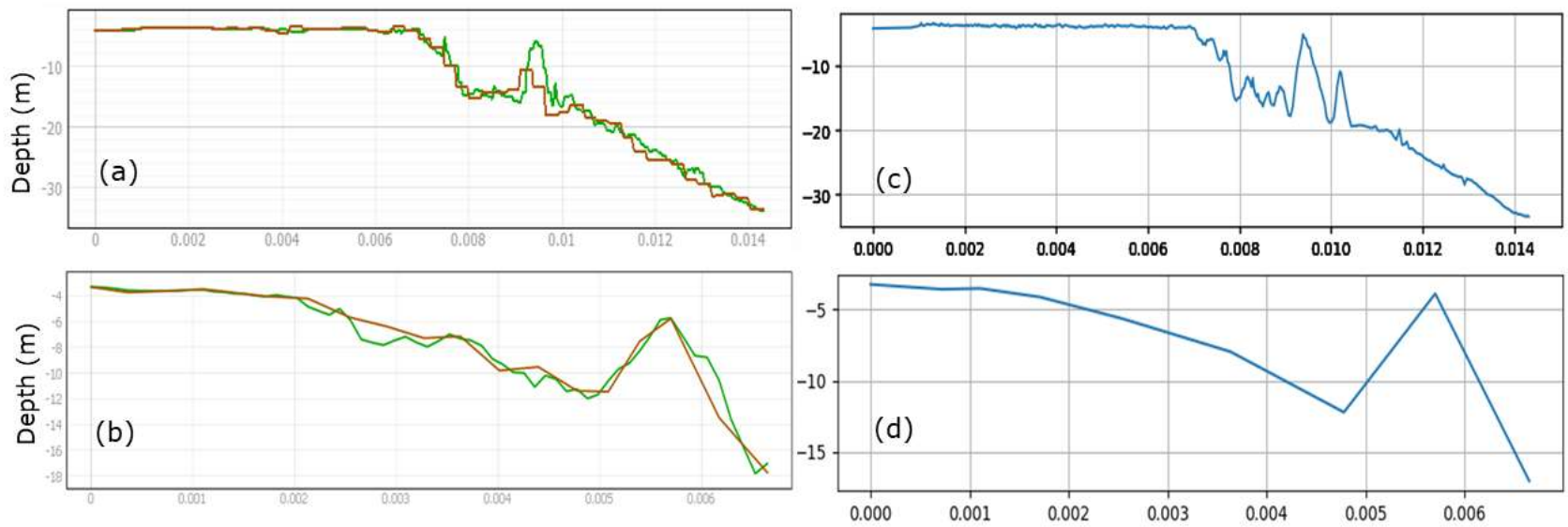

Figure 5. Cross profile showing comparison between SDB model from GWR applied on Sentinel-2A (green line) and Landsat 8 OLI/TIRS (brown line) for AoI-1 (a) and AoI-2 (b); and the profiles of their related SBES measurements for AoI-1 (c) and AoI-2 (d). The cross-profile location is indicated as black line in Figure 6.

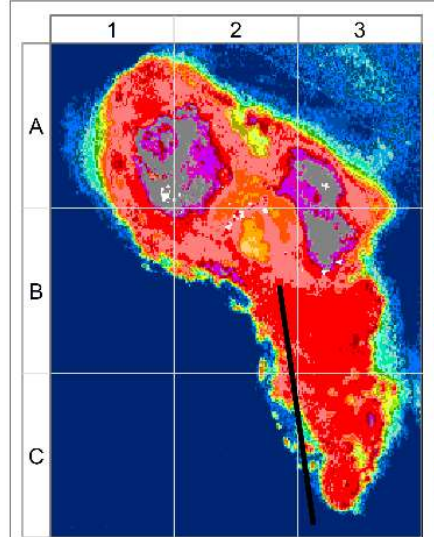

(a)

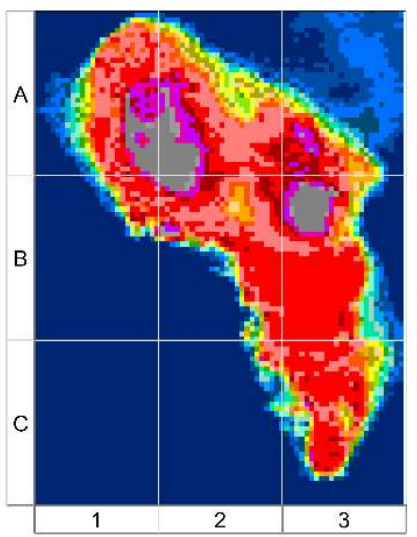

(d)

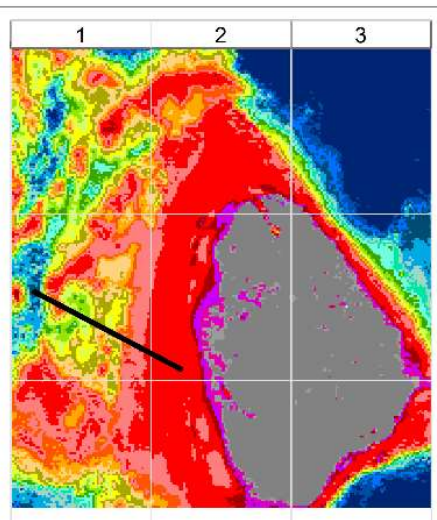

(b)

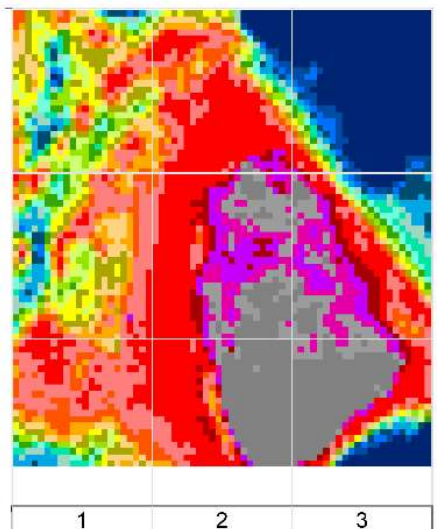

(e)

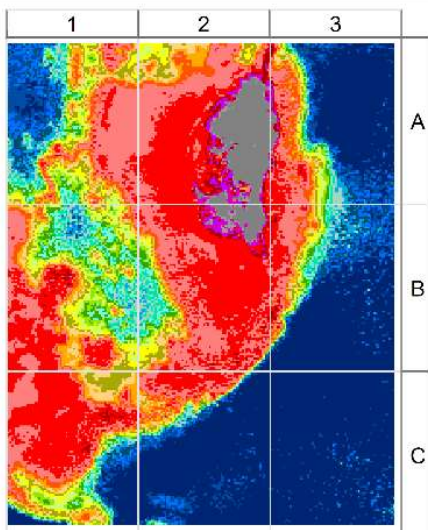

(c)

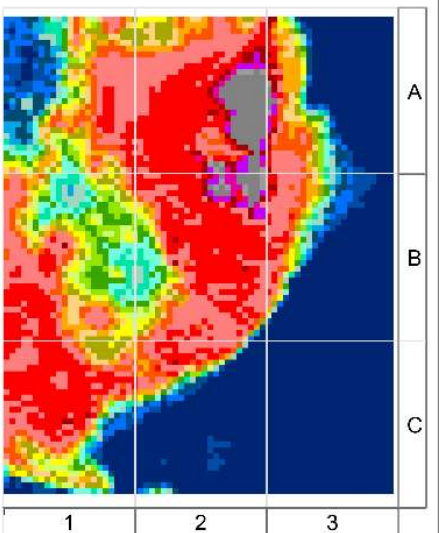

(f)

Depth (m)
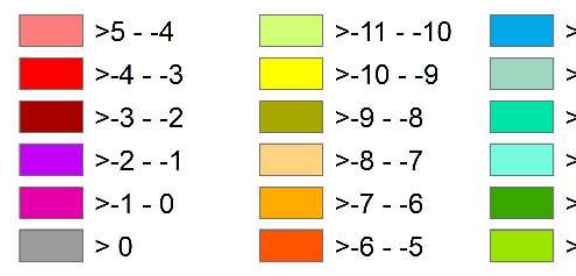

$>-17--16$
$>-16--15$
$>-15--14$
$>-14--13$
$>-13--12$
$>-12--11$
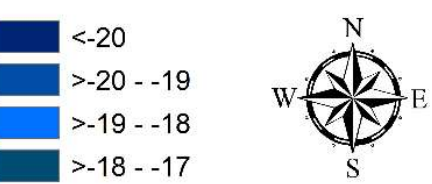

Figure 6. Shallow water depth model based on AGWR approach using 75\% training data from Sentinel-2A (a-c) and Landsat 8 OLI/TIRS (d-f) applied on three area of interest (a, d) AoI-1, (b, e) AoI-2, and (c, f) AoI-3. Black lines in (a, b) are the cross profiles location when comparing depth information from images. 
To further evaluate the quality of our model, we generated cross profiles for the two AoIs as in Figure 5. We can see that AGWR model applied on Sentinel-2A and Landsat 8 OLI/TIRS images produced a fit line in shallow water area (less than $10 \mathrm{~m}$ depth), while in the deeper area both lines were shifted. However, from Figures $5 \mathrm{a}$ and $5 \mathrm{c}$, we can see that Sentinel-2A profile (green line) has a similar pattern with the profile of SBES measurement (blue line).

Figure 6 presents the visualisation of the SDB model from both Sentinel-2A and Landsat 8 OLI/TRS. In general, both images have a similar depth pattern; however, Sentinel-2A images provide more detailed depth information due to the fact that it has a higher spatial resolution. Sentinel-2A with $10 \mathrm{~m}$ resolution produced more detailed depth information compared to Landsat $8 \mathrm{OLI} / \mathrm{TIRS}$ with $30 \mathrm{~m}$ resolution. The results also demonstrated that the use of higher resolution improved the accuracies of the model because when the spatial resolution decrease, it gives effect to the spatial heterogeneity of images. Despite the fact that both images produced similar patterns, the differences are clearly seen in some places, for example Figure 6a,d grid cells A1 and A2. Sentinel-2A detected the boundary between water and land while Landsat 8 OLI/TIRS recognized it as water, for example in Figure 6b,e grid cells B2, and B3.

\section{CONCLUSION AND FURTHER WORK}

In this study, we performed SDB modelling with AGWR approach with different sets of training data and satellite images. The statistical and visual evaluation presented in this study shows the capabilities of AGWR to estimate depth in clear shallow water. From RMSE and TVU values, we argue that AGWR is promising as a method to derive depth information from satellite images and can further be applied in other areas in Indonesia.

However, improvements are still needed for the consistency of the SDB model, for instance a careful check on the datasets used in this research. Information on the accuracy of the in-situ data is important to have a better understanding of the datasets. Moreover, the pre-processing step of the satellite images should be carried out in a more comprehensive way, for example by comparing different atmospheric correction approaches.

Finally, based on our research, it was obvious that higher resolution images produced better results. Hence, future study using higher resolution data sets is necessary to be able to result in more detailed information in the shallow water area.

\section{ACKNOWLEDGEMENTS}

The data used in this paper were provided by the Center for Marine and Coastal Environment Mapping of the Indonesian Geospatial Information Agency (BIG). The research also benefits from the Indonesian Endowment Fund for Education (LPDP), Republic of Indonesia.

\section{REFERENCES}

Binbin, L., Harris, P., Charlton, M., Bruns-, C., Nakaya, T., \& Gollini, I. (2019). Package 'GWmodel .'

Bramante, J. F., Raju, D. K., \& Sin, T. M. (2013). Multispectral derivation of bathymetry in Singapore's shallow, turbid waters. International Journal of Remote Sensing, 34(6), 2070-2088. https://doi.org/10.1080/01431161.2012.734934

Brunsdon, C., Fotheringham, A. S., \& Charlton, M. E. (1996). Geographically Weighted Regression: A Method for
Exploring Spatial Nonstationarity. Geographical Analysis. https://doi.org/10.1111/j.15384632.1996.tb00936.x

Dewi, R. S., Hartanto, P., Oktaviani, N., Pujawati, I., Nursugi, N., \& Aditya, S. (2019). Satellite-derived bathymetry to improve bathymetric map of Indonesia. https://doi.org/10.1117/12.2540779

Evagorou, E., Mettas, C., Agapiou, A., Themistocleous, K., \& Hadjimitsis, D. (2019). Bathymetric maps from multitemporal analysis of Sentinel-2 data: The case study of Limassol, Cyprus. Advances in Geosciences, 45(1988), 397-407. https://doi.org/10.5194/adgeo-45-397-2019

Fotheringham, A. S., Charlton, M. E., \& Brunsdon, C. (1998). Geographically weighted regression: a natural evolution of the expansion method for spatial data analysis. Environment and Planning A. https://doi.org/10.1068/a301905

Geological Interior Survey, D. (2016). Landsat 8 (L8) Science Data User's Handbook. America, 8(1993), 1993-1993.

Geyman, E. C., \& Maloof, A. C. (2019). A Simple Method for Extracting Water Depth From Multispectral Satellite Imagery in Regions of Variable Bottom Type. Earth and Space Science. https://doi.org/10.1029/2018EA000539

Gollini, I., Lu, B., Charlton, M., Brunsdon, C., \& Harris, P. (2015). GWmodel: an R package for exploring spatial heterogeneity. Journal of Statistical Software, 63(17), 150. https://doi.org/10.1080/10095020.2014.917453

Green, E. P., Mumby, P. J., Edwards, A. J., \& Clark, C. D. (2000). Remote Sensing Handbook for Tropical Coastal Management. In Coastal Management Sourcebooks 3.

Hamylton, S. M., Hedley, J. D., \& Beaman, R. J. (2015). Derivation of high-resolution bathymetry from multispectral satellite imagery: A comparison of empirical and optimisation methods through geographical error analysis. Remote Sensing, 7(12), 16257-16273. https://doi.org/10.3390/rs71215829

International Hydrographic Organization. (2008). IHO Standards for Hydrographic Surveys (S-44) 5th Edition.

Kanno, A., Koibuchi, Y., \& Isobe, M. (2012). Shallow Water Bathymetry from Multispectral Satellite Images: Extensions of Lyzenga's Method for Improving Accuracy. Coastal Engineering Journal, 53(4), 431-450. https://doi.org/10.1142/s0578563411002410

Kanno, A., \& Tanaka, Y. (2012). Modified lyzenga's method for estimating generalized coefficients of satellite-based predictor of shallow water depth. IEEE Geoscience and Remote Sensing Letters, 9(4), 715-719. https://doi.org/10.1109/LGRS.2011.2179517

Kanno, A., Tanaka, Y., Kurosawa, A., \& Sekine, M. (2013). Generalized Lyzenga's Predictor of Shallow Water Depth for Multispectral Satellite Imagery. Marine Geodesy, 36(4), 365-376. https://doi.org/10.1080/01490419.2013.839974

Lu, B., Harris, P., Charlton, M., \& Brunsdon, C. (2014). The GWmodel R package: Further topics for exploring spatial heterogeneity using geographically weighted models. Geo-Spatial Information Science, 17(2), 85-101. https://doi.org/10.1080/10095020.2014.917453

Lyzenga, D. R. (1978). Passive remote sensing techniques for mapping water depth and bottom features. Applied Optics, 17(3), 379. https://doi.org/10.1364/ao.17.000379

Lyzenga, D. R. (1985). Shallow-water bathymetry using combined lidar and passive multispectral scanner data. International Journal of Remote Sensing, 6(1), 115-125. https://doi.org/10.1080/01431168508948428

Lyzenga, D. R., Malinas, N. P., \& Tanis, F. J. (2006). Multispectral bathymetry using a simple physically based 
algorithm. IEEE Transactions on Geoscience and Remote Sensing, 44(8), 2251-2259. https://doi.org/10.1109/TGRS.2006.872909

Manessa, M. D. M., Haidar, M., Hartuti, M., \& Kresnawati, D. K. (2018). Determination of the Best Methodology for Bathymetry Mapping Using Spot 6 Imagery: a Study of 12 Empirical Algorithms. International Journal of Remote Sensing and Earth Sciences (IJReSES), 14(2), 127. https://doi.org/10.30536/j.jireses.2017.v14.a2827

Manessa, M. D. M., Kanno, A., Sekine, M., Haidar, M., Yamamoto, K., Imai, T., \& Higuchi, T. (2016). SatelliteDerived Bathymetry Using Random Forest Algorithm and Worldview-2 Imagery. Geoplanning: Journal of Geomatics and Planning, 3(2), 117. https://doi.org/10.14710/geoplanning.3.2.117-126

Mishra, D., Narumalani, S., Rundquist, D., \& Lawson, M. (2013). Benthic Habitat Mapping in Tropical Marine Environments Using QuickBird Multispectral Data. Photogrammetric Engineering \& Remote Sensing, 72(9), 1037-1048. https://doi.org/10.14358/pers.72.9.1037

Polcyn, F. C., \& Rollin, R. A. (1969). Remote Sensing Techniques for the Location and Measurement of Shallow-Water Features. Proceedingsofthe Sixth International Symposium on Remote Sensing of the Environment.

Sagawa, T., Yamashita, Y., Okumura, T., \& Yamanokuchi, T. (2019). Satellite derived bathymetry using machine learning and multi-temporal satellite images. Remote Sensing. https://doi.org/10.3390/rs11101155

Said, N. M., Mahmud, M. R., \& Hasan, R. C. (2017). SatelliteDerived Bathymetry: Accuracy Assessment on Depths. The International Archives of the Photogrammetry, Remote Sensing and Spatial Information Sciences, XLII(October), 159-164.

Vinayaraj, P. (2017). Development of Algorithms for Near-shore Satellite Derived Bathymetry Using Multispectral Remote Sensing Images. 1.

Vinayaraj, P., Raghavan, V., \& Masumoto, S. (2016). SatelliteDerived Bathymetry using Adaptive Geographically Weighted Regression Model. Marine Geodesy, 39(6), 458-478. https://doi.org/10.1080/01490419.2016.1245227

Wicaksono, P. (2015). Perbandingan Akurasi Metode Band Tunggal dan Band Rasio Untuk Pemetaan Batimetri Pada Laut Dangkal Optis. Simposium Nasional Sains Geoinformasi IV, 792. Yogyakarta. 